УДК 330.322 .54

\title{
Economic Evaluation \\ of Regional Innovative Projects \\ in the Sphere of Biomedicine
}

\author{
Oleg N. Shishatskiy* \\ Krasnoyarsk Department for Forecasting \\ and Economic Development of the Region at Institute \\ of Economics and Industrial Engineering SB RAS \\ 50 Akademgorodok, Krasnoyarsk, 660036, Russia
}

Received 01.11.2015, received in revised form 03.02.2016, accepted 22.05.2016

The article deals with the cost-effectiveness analysis of innovative projects in the sphere of biomedicine. The analysis of these projects makes it possible to estimate the economic benefits of the projects and will contribute to the commercialization of intellectual property created in our region. The development strategy of medical science in the Russian Federation until 2025 calls for a cluster principle of organization. It is proposed to use a public-private partnership in the form of concession as a model for cluster creation. The selection of innovative biomedical projects should be carried out using their cost-effectiveness analysis. It is noted that the use of real options is a way to quantify the project management flexibility.

Keywords: project evaluation, efficiency, biomedicine, biotechnology, real options.

DOI: 10.17516/1997-1389-2016-9-2-223-232.

(c) Siberian Federal University. All rights reserved

* Corresponding author E-mail address: shishatskiy@mail.ru 


\section{Экономическая оценка}

\section{региональных инновационных проектов в сфере биомедицины}

О.Н. Шишацкий

Красноярский отдел прогнозирования и экономического развития региона Института экономики и организацчии промышленного производства СО РАН Россия, 660036, Красноярск, Академгородок, 50

В статье рассмотрень необходимость и методы оценки экономической эффективности инновационных проектов в сфере биомедицины. Применение описанных методов позволит оценить экономический эффект от реализации проектов и будет способствовать коммерцуиализации интеллектуальной собственности, создаваемой в том числе в Красноярском крае. Стратегия развития медицинской науки в РФ до 2025 г. предусматривает кластерный принции организации. В качестве модели создания кластера предлагается государственночастное партнерство в форме концессии. Отбор инновационных биомедицинских проектов следует осуществлять с использованием оценки их экономической эффективности. Отмечается, что применение метода реальных опционов является наиболее оптимальным способом количественной оценки гибкости управления проектами.

Ключевые слова: оценка проектов, эффективность, биомедицина, биотехнологии, реальные опичионь.

\section{Введение}

Здоровье населения - неоценимый ресурс, который выгоден не только для различных секторов экономики государства, но также для общества в целом. В настоящее время развитие биомедицины и еe приложений является ключевым направлением государственной политики стран по причине своей стратегической значимости в сфере гуманитарного благополучия и национальной независимости. Экономические выгоды от здоровья населения заключаются в повышении производительности труда, формировании более продуктивных трудовых ресурсов, сокращении расходов на пособия по болезни и социальную помощь.

Быстро растущий мировой рынок высокотехнологической медицинской помощи с огромным спросом на инновационную продукцию (знания, технологии, продукты и т.д.) служит дополнительной причиной приоритетности биомедицинских исследований. Медицина направлена на борьбу с социально значимыми заболеваниями сердечно-сосудистой системы, онкологией, патологиями, вызванными вирусными инфекциями, и т.д., которые сегодня неизлечимы и ведут к потере трудоспособности, одновременно являясь причинами огромного количества смертей 
вне зависимости от уровня экономического развития страны и размера доходов ее граждан. Эти факторы создают ситуацию, способствующую развитию биомедицинских исследований, которые обеспечивают получение новых знаний о строении и функционировании организма человека, служат основой для научно-технологического развития медицинской и фармакологической отраслей, обеспечивающего национальное благополучие стран и независимость от импорта биомедицинских изделий и препаратов. Все перечисленное обусловливает повышенный интерес к биомедицине в развитых странах.

По мнению экспертов, отставание российской биомедицины от мировых лидеров этого направления составляет 15-20 лет; отмечается, что в мировой науке Россия занимает весьма слабую позицию по этому направлению, что во многом объясняется тем, что ранее (еще в СССР) приоритеты в научных исследованиях страны сложились не в пользу наук о жизни.

В последние годы для изменения этой ситуации в РФ принят ряд мер:

1. Разработаны и утверждены «Комплексная программа развития биотехнологий в Российской Федерации на период до 2020 года», «Стратегия развития медицинской науки в РФ на период до 2025 г.», федеральная целевая программа «Развитие фармацевтической и медицинской промышленности Российской Федерации на период до 2020 года и дальнейшую перспективу».

2. Созданы технологические платформы «Медицина будущего», «Биоиндустрия и биоресурсы - БиоТех2030», «Биоэнергетика».

3. Реализуется программа развития инновационных территориальных кластеров. В общий перечень из 25 кластеров вошли семь, специализирующихся в сфере медицины и фармацевтики.
Bсе указанные меры направлены на изменение в России в ближайшей перспективе вектора развития биомедицинских технологий. Так, в «Стратегии развития медицинской науки в РФ на период до 2025 г.» (Стратегия), которая утверждена Правительством в 2012 г., развитие биомедицинских исследований объявлено государственным приоритетом. Стратегия направлена на реализацию мероприятий государственной политики в сфере здравоохранения и включает мероприятия по разработке инновационной продукции, критически важных технологий и компетенций. В ней поставлена цель развития передовых технологий медицинской науки и внедрения на их основе инновационных продуктов, обеспечивающих сохранение и улучшение здоровья населения.

Экономика Красноярского края преимущественно имеет экспортно-сырьевую ориентацию, промышленность в регионе отличается высокой степенью физического и морального износа, она содержит сравнительно низкую долю высокотехнологичной продукции в общем объеме реализации продуктов и услуг, значительная часть оборудования для базовых отраслей импортируется.

В настоящее время в стране поставлены приоритетные задачи развития экономики стимулирование инновационной деятельности, модернизация народного хозяйства на основе знаний. Если Красноярский край будет отставать в развитии и становлении инновационной деятельности, это приведет регион к негативному сценарию развития с полной ориентацией на сырьевые секторы экономики, отсутствию перевооружения промышленности, потере научного и кадрового потенциала, экономическим потерям региона в целом.

Для стимулирования инновационной деятельности в регионе в ноябре 2011 г. 
утверждена «Стратегия инновационного развития Красноярского края на период до 2020 года». Цель Стратегии - достижение долгосрочной конкурентоспособности Красноярского края в национальном и мировом масштабе на основе развития экономики знаний через формирование необходимых условий для создания инноваций и модернизации производства.

В регионе ведется работа по созданию эффективной системы реализации научных исследований и внедрения в клиническую практику инновационных биомедицинских разработок, включая создание новых лекарственных препаратов и медицинских изделий, оказанию населению высокотехнологичной медицинской помощи (Распоряжение губернатора Красноярского края № 32-рг, 2015).

\section{Суть инновационных проектов}

\section{в сфере биомедицины}

Инновационные биомедицинские проекты отличаются тем, что, помимо создания производства самого инновационного продукта и обеспечения его поставок на рынок, требуется обеспечить длительное и затратное прохождение продуктом всех этапов, которые необходимы для получения нормативного разрешения на применение новых биомедицинских препаратов и технологий.

Здравоохранение является локальной системой в каждом отдельно взятом государстве, однако биомедицинский бизнес - это глобальный бизнес. Успех компаний, действующих в сфере биомедицинских технологий, невозможен в отдельно взятой стране. Сегодня биотехнологические компании создают, разрабатывают и выводят на рынок биомедицинские продукты для пациентов во всем мире. Таким образом, реализация инновационных биомедицинских проектов должна начинаться с лицензирования интеллек- туальной собственности (ИС) на тех рынках, на которых в дальнейшем будет действовать компания.

Все новые продукты медицинского назначения, прежде чем они будут допущены на рынок, должны быть проверены на безопасность и эффективность. В различных странах действуют свои нормативные документы, peгулирующие порядок допуска фармакологической и медицинской продукции на рынок. Так, в России разработка и исследования лекарственных средств регулируется отдельным Федеральным законом (Федеральный закон ..., 2010), положения которого гармонизированы с общей схемой, действующей во всем мире. Общая схема получения нормативного разрешения на применение новых лекарственных препаратов, изделий и технологий, которая действует в мире, состоит из следующей серии этапов.

1. Доклинические исследования. Изучение нового медицинского продукта, предшествующее клиническим исследованиям, проводится на лабораторных животных и в культурах клеток. Проверяется токсичность и активность препарата или изделия. Проведение первоначальных доклинических исследований обычно осуществляется в лаборатории, разрабатывающей новый продукт. По результатам доклинических исследований составляются соответствующие отчеты, препарат регистрируется и допускается до клинических фаз исследований.

2. Клинические исследования. Следующим этапом разработки медицинского продукта служит проведение клинических исследований (КИ). Традиционно КИ разделяют на фазы, каждая из которых является более масштабной, детальной и дорогой, чем предыдущие. Всего существует шесть таких фаз (фазы 0-V), однако чаще всего исследования ограничиваются первыми тремя. 
3. Заявка на одобрение нового лекарственного средства. Завершающий шаг на пути нового медицинского продукта на рынок - подача заявки на регистрацию изделия в соответствующий регуляторный орган системы здравоохранения той или иной страны с целью получить одобрение для его использования в медицинской практике. Для США это управление по контролю качества пищевых продуктов и лекарственных средств (Food and Drug Administration - FDA), в Европе - Европейское агентство по лекарственным средствам (European Medicines Agency - EMEA), в России - Министерство здравоохранения Российской Федерации (Минздрав РФ). Для регистрации продукта разработчик передает в соответствующий регуляторный орган регистрационное досье, которое включает в себя описание процесса производства продукта медицинского назначения, данные о его качестве и результатах клинических исследований. Если заявка получает одобрение, новый продукт поступает в продажу.

Срок времени с момента начала разработки лекарственного препарата или изделия в лаборатории до одобрения его продажи на рынке и применения в клинической практике в среднем составляет от 10 до 15 лет. Медианная стоимость разработки одного препарата сейчас равна $\$ 1,7$ млрд (Российская венчурная компания..., 2013).

Следует отметить, что оценка экономической эффективности проектов разработки медицинских изделий является более сложной и трудоемкой работой, чем оценка проектов разработки лекарственных препаратов, так как отсутствуют публикации, посвященные анализу вероятности успеха, продолжительности и затратности КИ при разработке различных видов медицинских изделий.

\section{Биомедицинские проекты}

на основе научных разработок

Института биофизики СО РАН и Сибирского федерального университета

В Красноярске в сфере биотехнологии сложилась научная школа, которая ориентирована на получение и изучение свойств природных биоразлагаемых полимеров семейства полигидроксиалканоатов (ПГА).

Одно из наиболее актуальных направлений применения полимеров этого класса связано с биомедициной. Биополимеры ПГА обладают свойствами биоразлагаемости и биосовместимости, что делает их весьма перспективным материалом для создания инновационных биомедицинских изделий и технологий.

Исследования биоразлагаемых полимеров ПГА проводятся в Институте биофиЗики СО РАН (ИБФ СО РАН) и Институте фундаментальной биологии и биотехнологии Сибирского федерального университета (ИФБиБТ СФУ). В этих организациях выполнен цикл пионерных фундаментальных исследований закономерностей синтеза разрушаемых полигидроксиалканоатов; найдены ключевые факторы, определяющие выходы, химическую структуру и физико-химические свойства полимеров; разработаны, реализованы и запатентованы процессы получения полимеров различного состава с высокими выходами на различных субстратах. Полученные результаты опубликованы в представительной серии журнальных статей и защищены патентами.

Процесс получения биополимеров ПГА впервые в России был масштабирован и реализован в рамках проекта МНТЦ на опытном производстве, созданном в Институте биофизики СО РАН. В ходе эксплуатации этого производства в 2004-2006 гг. было установлено, что его основные технико-экономические по- 
казатели соответствуют расчетным; получены первые в РФ крупные партии полимеров для технологических и биомедицинских испытаний и исходные данные для последующего масштабирования технологии (Volova, 2004; Волова с соавт., 2006). Далее в СФУ в результате выполнения университетом двух мегапроектов по постановлениям Правительства РФ № 219 и 220 от 9 апреля 2010 г. была создана инновационная структура по биотехнологии разрушаемых биополимеров. Данная структура не имеет аналогов в России и состоит из опытного производства полимеров, аналитического подразделения и серии лабораторий для обработки полимеров, получения специальных полимерных изделий и их изучения (Киселев с соавт., 2014).

К настоящему времени имеется принципиальная возможность получения изделий биомедицинского назначения: пленочных покрытий, шовных нитей, матриксов и конструкций для тканевой инженерии, а также пролонгированных систем доставки лекарственных веществ (Volova et al., 2013). Эти изделия перспективны для многих направлений, включая сердечнососудистую хирургию, ортопедию, урологию, стоматологию и др. Области применения ПГА в медицине и потенциальные медицинские изделия и технологии показаны в табл.

Полученные результаты позволяют констатировать наличие в регионе значительного научного задела для развертывания КИ высокотехнологичных изделий из ПГА для повышения качества лечения и результативности медицинских технологий.

\section{Предложения по развитию}

\section{биомедицинского направления}

в г. Красноярске

В «Стратегии развития медицинской науки в РФ на период до 2025 г.» говорит- ся об организации современной науки по кластерному принципу и необходимости формирования научно-образовательнопроизводственных кластеров, объединяющих научно-исследовательские лаборатории, факультеты и кафедры ведущих вузов страны, осуществляющих подготовку специалистов соответствующего профиля, клиники научно-исследовательских центров и вузов, производственно-технологическую базу предприятий различной формы собственности. Одним из ключевых инструментов для отбора НИИ и вузов, которые будут реализовать свои инновационные биомедицинские проекты в кластере, должна стать экономическая оценка эффективности этих проектов. С учетом этого положения в Красноярском крае предусмотрена разработка предложений по формированию научно-технологических проектов «полного цикла» на основе разработок научно-исследовательских институтов, образовательных организаций высшего профессионального образования и инновационных организаций Красноярского края (Распоряжение губернатора Красноярского края № 32-рг..., 2015). В качестве модели создания кластера целесообразно использовать государственно-частное партнерство в форме концессии. В качестве аналога можно рассмотреть создание в Новосибирской области в 2012 г. инновационного кластера в сфере медицины, ядром которого является специализированный технопарк полного цикла для сферы медицины на базе ФГБУ «ННИИТО им. Я.Л. Цивьяна» Минздрава России.

Экономическая оценка эффективности потенциальных инновационных биомедицинских проектов требуется для выбора приоритетных для развития проектов, обладающих максимальными положительными эффектами. Для количественной экономической оценки потенциала инновационных 
Таблица. Потенциальные возможности применения ПГА в медицине

\begin{tabular}{|c|c|}
\hline Область медицинского применения & Медицинские изделия и технологии \\
\hline 1. Сердечно-сосудистая хирургия & $\begin{array}{l}\text { - клапаны сердца, сконструированные по } \\
\text { технологии клеточной и тканевой инженерии } \\
\text { - пленки в качестве барьерного средства для } \\
\text { разделения перикардия и грудины } \\
\text { - повышение биосовместимости сосудистых } \\
\text { эндопротезов (покрытие стентов) } \\
\text { - сосудистые протезы (стенты) }\end{array}$ \\
\hline 2. Хирургия & - шовные нити, барьерные мембраны \\
\hline $\begin{array}{l}\text { 3. Ортопедия, челюстно-лицевая хирургия, } \\
\text { краниопластика - реконструкция дефектов } \\
\text { костной ткани }\end{array}$ & $\begin{array}{l}\text { - заменитель костной ткани } \\
\text { - штифты } \\
\text { - пластины для закрытия дефектов плоских } \\
\text { костей черепа и лица } \\
\text { - трехмерные матриксы из ПГА и композитов с } \\
\text { керамиками } \\
\text { - гибкие пленки и мембраны из ПГА } \\
\text { - пломбировочный костнопластический материал }\end{array}$ \\
\hline $\begin{array}{l}\text { 4. Трубчатые эндопротезы (стенты) для } \\
\text { реконструктивной хирургии желчевыводящих } \\
\text { путей }\end{array}$ & $\begin{array}{l}\text { - полностью резорбируемые эндобилиарные } \\
\text { стенты } \\
\text {-металлические стенты с полимерным покрытием }\end{array}$ \\
\hline $\begin{array}{l}\text { 5. Биосовместимые покрытия полимерных } \\
\text { эндопротезов }\end{array}$ & $\begin{array}{l}\text { - повышение биосовместимости сетчатых } \\
\text { эндопротезов, применяемых при операциях } \\
\text { грыжесечения }\end{array}$ \\
\hline $\begin{array}{l}\text { 6. Полимерные носители из ПГА для } \\
\text { депонирования и доставки лекарственных } \\
\text { препаратов }\end{array}$ & $\begin{array}{l}\text { - разработка адресных лекарственных форм } \\
\text { препаратов с пролонгированным действием, } \\
\text { пригодных для различных способов введения in } \\
\text { vivo }\end{array}$ \\
\hline 7. Тканевая инженерия & $\begin{array}{l}\text { - изготовление носителей (scaffolds) для } \\
\text { выращивания клеток различного происхождения, } \\
\text { а также для направленной дифференцировки } \\
\text { стволовых клеток и конструирования } \\
\text { тканеинженерных графтов }\end{array}$ \\
\hline
\end{tabular}

проектов обычно рассчитывают два показателя:

- коммерческая (финансовая) эффективность, которая учитывает выгоды и затраты при реализации проекта для совокупности частных субъектов (участников проекта);

- общественная (экономическая, социально-экономическая) эффективность, которая учитывает последствия реализации проекта с точки зрения общества в целом.

\section{Экономическая оценка эффективности инновационных проектов}

Для развития инновационных проектов необходимы венчурные инвестиции, и инвесторы заинтересованы в финансировании наиболее эффективных, имеющих высокий коммерческий потенциал проектов. Поэтому в представленной статье рассмотрим оценку коммерческой эффективности биомедицинских инновационных проектов.

Для оценки коммерческой эффективности инвестиционно-инновационных проек- 
тов преимущественно применяется доходный подход. Главная идея подхода состоит в определении ценности проекта на основе текущей ценности приходящихся на данный проект ожидаемых в будущем (прогнозируемых) денежных потоков.

Основа подхода - метод дисконтированных денежных потоков (ДДП), который служит стандартом для проведения оценки инвестиционных проектов на протяжении многих лет. Теория реальных опционов (РО) возникла более 30 лет назад как продолжение метода ДДП. Метод РО впервые был рассмотрен в 1977 г. в статье (Myers, 1977). В основе теории лежит тот факт, что когда принимается решение о запуске проекта, в отношении его дальнейшего развития существует достаточно много неопределенностей. Оценка с использованием РО получает все большее распространение и рассматривается как возможная альтернатива методу ДДП в сфере оценки инвестиционно-инновационных проектов.

Оба метода имеют свои преимущества и недостатки. Например, использование метода ДДП при оценке фармацевтических проектов на ранней стадии в большинстве случаев дает отрицательные результаты, однако в целом отрасль остается прибыльной. Это причина недоверия к оценкам и основанным на них рекомендациям. Несмотря на отрицательные оценки, полученные методом ДДП, освоение проектов ранних стадий продолжается, что часто приводит к отрицанию количественных методов оценки.

Преимуществом метода ДДП в сравнении с методом реальных опционов является его простота. Однако эта простота служит следствием нескольких существенных допущений. Метод ДДП предполагает, что состояние рынка неизменно, т.е., однажды спрогнозировав максимальные объемы продаж, мы больше не изменяем значение этого прогноза.
Можно возразить, что прогноз максимальных объемов продаж соответствует среднему значению того, что мы ожидаем. Что бы ни произошло, существует одинаковая вероятность того, что реальный результат будет выше или ниже спрогнозированного значения. В среднем продажи будут равны прогнозам. Почему нельзя просто использовать в расчетах прогнозы максимальных объемов продаж?

В этом подходе скрыты две опасности. Первая состоит в том, что, принимая один сценарий, т.е. среднее значение, мы рискуем принять его как само собой разумеющееся, не требующее доказательств. Это может привести к излишней зависимости от сценария, который является лишь смутной оценкой. Вторая заключается в том, что сведение будущего только к одному сценарию препятствует рассмотрению альтернатив, если выяснится неверность прогноза или необходимости его корректировки в соответствии с новыми обстоятельствами. Это приводит к неспособности статического управления реагировать на рыночные изменения. Конечно, это не означает, что управленцы, пользующиеся методом ДДП, ничего не делают. Метод ДДП предусматривает переоценку проекта в случае изменения ключевых факторов. Эта практика не зависит от метода оценки. Однако ДДП не принимает во внимание практику возможной корректировки проекта, оценка производится при условии, что менеджмент принял единовременное решение о старте проекта. Логично предположить, что компания меняет свои планы, если один из критических показателей ухудшается или, наоборот, превосходит ожидания. У компании имеется выбор опций: уменьшить масштаб, приостановить, прекратить полностью или в благоприятных условиях ускорить или расширить проект. Менеджмент принимает решения с целью увеличения стоимости проекта. Некоторые 
сценарии, часто не самые вероятные, предполагают решения, которые не были заложены в первоначальный план проекта. Метод ДДП не предусматривает такую управленческую гибкость.

Метод РО допускает, что решения в осуществлении проекта или жизни компании могут или должны быть приняты в зависимости от будущего состояния рынка. Эти условия могут значительно отличаться от текущих рыночных условий; тем не менее будущие решения могут только предполагаться с определенной степенью вероятности. Следовательно, менеджмент должен сохранять гибкость, чтобы реагировать на изменения. Гибкость используется либо для увеличения доходов, либо для уменьшения расходов. В любом случае целью гибкости является увеличение стоимости. Если проект предусматривает такие опции, которые позволяют менеджменту влиять на ход проекта, они должны учитываться при оценке. Гибкость всегда используется для увеличения стоимости проекта или компании, следовательно, метод оценки, который учитывает эту гибкость, в результате оценивает лучше, чем методы, которые ее не учитывают. Этот вариант создания стоимости не оценивается методом ДДП.

Новизна метода РО в сравнении с методом ДДП заключается в том, что ряд будущих решений по поводу проекта или компании зависит от соответствующего состояния рынка, а не смутно предполагается. В теории РО развитие проекта или компании зависит от изменяющихся рыночных условий, тогда как при использовании метода ДДП течение проекта предопределено независимо от обстоятельств.

Для корректного моделирования решений необходимо смоделировать условия или параметры, от которых они зависят. Для этого в теории РО используются приемы из сферы финансовых опционов, имеющие отношение к схожим вопросам. Из-за колебаний рынка вначале не ясно, какой выигрыш получит владелец производного финансового инструмента (опциона) по истечении срока.

При использовании производных финансовых инструментов различные способы их исполнения предопределены, а в реальных опционах менеджмент должен самостоятельно определить различные способы перестройки бизнеса компании в соответствии с изменяющимися обстоятельствами. Однако компания не может адаптировать свои решения к меняющимся обстоятельствам в последний момент. Необходимо измерить эту гибкость. Некоторые проекты могут иметь несколько возможных альтернатив, следовательно, гибкость важна и представляет значительную часть оценки стоимости. Другие проекты нежелательно изменять, это в основном прибыльные проекты, их возможная гибкость ничего не стоит.

\section{Заключение}

Оценка реализуемых в Красноярском крае проектов в области биомедицины, в частности по инновационным биоразрушаемым биополимерам и изделиям из них, позволит определить экономический эффект от их реализации, будет способствовать привлечению инвестиций в проекты и коммерциализации интеллектуальной собственности, создаваемой в регионе. Исходя из «Стратегии развития медицинской науки в РФ до 2025 г.», в качестве модели создания кластера необходимо использовать государственно-частное партнерство в форме концессии. Для отбора НИИ и вузов, которые будут реализовать свои инновационные биомедицинские проекты в кластере, целесообразно проведение экономической оценки их эффективности с применением метода РО. 


\section{Список литературы}

Волова Т.Г., Войнов Н.А., Муратов В.С., Бубнов Н.В., Гурулев К.В., Калачева Г.С., Горбунова Н.В., Плотников В.Ф., Жила Н.О., Шишацкая Е.И., Беляева О.Г., Кожевников, И.В. (2006) Опытное производство разрушаемых биополимеров. Биотехнология, 6: 28-34 [Volova T.G., Voinov N.A., Muratov V.S., Bubnov N.V., Gurulev K.V., Kalacheva G.S., Gorbunova N.V., Plotnikov V.F., Zhila N.O., Shishatskaya E.I., Beliayeva O.G., Kozhevnikov I.V. (2006) Pilot production of biodegradable polymers. Biotechnology [Biotekhnologiya], 6: 28-34 (in Russian)]

Киселев Е.Г., Демиденко А.В., Барановский С.В., Волова Т.Г. (2014) Масштабирование технологии синтеза биодеградируемых полигидроксиалканоатов в условиях опытного производства. Журнал Сибирского федерального университета. Биология, 7: 134-147 [Kiselev E.G., Demidenko A.V., Baranovskiy S.V., Volova T.G. (2014) Scaling of biodegradable polyhydroxyalkanoates synthesis technology in pilot production conditions. Journal of Siberian Federal University. Biology [Zhurnal Sibirskogo federalnogo universiteta. Biologiya], 7: 134-147 (in Russian)]

Распоряжение губернатора Красноярского края № 32-рг «О создании рабочей группы для подготовки предложений по формированию биомедицинского кластера в Красноярском крае», 6 февраля 2015 г. [Order of the governor of Krasnoyarsk Territory No 32-rg "On the establishment of a working group for formulation of proposals on formation of a biomedical cluster in Krasnoyarsk Territory", February 6, 2015. (in Russian)]

Российская венчурная компания, Аналитический отчет «Глобальные тренды в биофармацевтических технологиях: 2013» (2013) [Russian Venture Company, Analytical report "Global trends in biopharmaceutical technologies: 2013” (2013) (in Russian)]

Федеральный закон № 61 «Об обращении лекарственных средств», 12 апреля 2010 г. [Federal Law № 61 “On medicine circulation”, April 12, 2010 (in Russian)]

Myers S. (1977) Determinants of corporate borrowing. Journal of Financial Economics, 5: 147175. https://www2.bc.edu/ chemmanu/phdfincorp/MF891\%20papers/Myers\%201977.pdf

Volova T.G. (2004) Polyhydroxyalkanoates - plastic materials of the $21^{\text {st }}$ century: production, properties, application. NY, USA, Nova Science Pub., Inc., 282 p.

Volova T.G., Shishatskaya E.I., Sinskey A.J. (2013) Degradable polymers: production, properties and applications. New York, USA, Nova Sci. Publ. Inc., 380 p. 